without cleavage of the phosphate linkage. Whether an enzyme to reverse the structure, "Q insertase", also exists is not yet known. The complexity of these reactions is significant in view of the known fluctuation in $Q$ base content in Drosophila during metamorphosis, and the elevated content of $\mathrm{Q}^{*}$ in tumour tissue.

H. Kersten (University of Erlangen) reported on the origin of the methyl groups in thymine of tRNA in Grampositive organisms. In all but one out of some 20 tested the methyl group is synthesised at the macromolecular level by way of the folate pathway. In all other organisms, including mammals, that methyl group originates from S-adenosylmethionine. On the other hand, the methyl groups in thymine in the rRNA of Gram-positive organisms come from S-adenosylmethionine. It was pointed out that the folate pathway of synthesis must be the more primitive since this is the origin of the methyl group of thymine in DNA. Methylation by enzymes at the macromolecular level is probably a later development since it is the method used to imprint species individuality on DNA and in tRNA. An attempt to resolve the paradox of the two pathways for the methyl groups in tRNA and rRNA was attempted by W. Kersten by the suggestion that tRNA is more primitive than rRNA. This is an interesting suggestion for those interested in the evolution of biomacromolecules.

H. Aschoff and W. Kersten (Erlangen) reported on an 800-fold purification of tRNA 7-G transmethylase from $E$. coli. Starting with kilos of $E$. coli they obtained a protein of 300,000 daltons which produces only 7-meG in tRNA from $B$. subtilis in which a $G$ in the extra arm is not methylated. This signal achievement 15 years after their discovery of the transmethylase highlights the difficulty inherent in purifying these complex enzymes.

One session was devoted to the modification of mRNA in eukaryotes. This area, too, is becoming increasingly complex. For example, D. T. Dubin (Rutgers University) has found a hitherto unknown "capping" of Sindbis virus-specific mRNA with an $\mathrm{N}_{2-}$ dimethyl-7-monomethyl G.

It is interesting to note the impact of policies of governance of science on the particular field covered by the meeting. Pre-eminence in the technology of tRNA modification has now passed from America to Germany and Japan, and one reason for this must lie in the pattern of the granting mechanism in the USA since no one in his right mind would dare tackle such problems on a 2-year NSF grant. There have been two international conferences on nucleic acid modification in the past 2 years; the first one was convened by Italian colleagues and the current one by German workers. To neither of these conferences was a contributor from Great Britain invited, which may well be because the MRC decided a few years ago that the study of modification of nucleic acids should have a low priority for support. What a pity to exclude the people who initiated modern biochemistry from tackling one of the most challenging problems in the field.

\section{Mysterious meteorites}

\section{from $M$. G. Edmunds}

Some forty meteorite chemists and astrophysicists met for an international four-day workshop on isotopic abundance anomalies organised by the Department of Applied Mathematics and Astronomy, University College, Cardiff, and held at Gregynog Hall on August 10-13, 1976.

THE early history of the Solar System has always provided ample scope for speculation, yet recent experimental investigations of the isotopic composition of certain meteorites have provided even more food for thought. A class of meteorites, the carbonaceous chondrites, has traditionally been regarded as the best available sample (except for some volatile elements) of the material out of which the Solar System formed. It came as rather a surprise, therefore, when work in the past few years showed that the relative isotopic abundances of particular elements in these meteorites are anomalous in that they can differ significantly from the so-called "cosmic" abundance ratios which are based on an amalgam of meteoritic, solar spectra and solar wind data. The workshop at Gregynog evolved into discussion of two major topics. The first problem was to sort out the experimental evidence to see exactly which elements really do show isotopic anomalies, and the second was to sift through possible theoretical mechanisms which could account for the origin of these anomalies. The three main possibilities examined were: chemical fractionation of isotopes occurring within some region of the early solar nebula out of which solid planets condensed; the production of particular isotopes in nuclear reactions caused by irradiation of the nebula by

\section{Coated vesicles and clathrin}

In a recent squib in these columns, Matus suggested that the protein molecule, "clathrin", which forms the lattice-like coats around coated vesicles (Pearse, J. molec. Biol., 97, 93; 1975; Proc. natn. Acad. Sci. U.S.A., 73, 1255; 1976; Crowther et al., J. molec. Biol., 103, 785; 1976) should be renamed "cytonexin". His reason for this is that E. G. Gray had described a fibrous network in presynaptic terminals which he called a cytonet (J. Neurocytol., 1, 363; 1972; Brain Res., 62, 329 ; 1973). At that time, Gray noted that the bristles on coated vesicles were indistinguishable (in the electron microscope) from the surrounding cytoplasmic matrix. As Matus states, Gray (J. Neurocytol., 4,$315 ; 1975$ ) has since repudiated the existence of this cytonet, concluding that it is an artefact of fixation probably arising from the precipitation of cytoplasmic proteins. Despite this, Matus now wishes to preserve this cobweb from the past and make us believe that the cytonet still exists, and that its constituent molecules can be identified by electron microscopy as clathrin, the molecule of which the striking polyhedral coats of coated vesicles are made.

\section{B. M. F. Pearse}

\section{S. BRetscher}

A. I. Matus Replies: Pearse and Bretscher complain about my rehabilitation of the cytonet on the grounds that Gray has repudiated it (J. Neurocytol., 4, 315; 1975). However in that paper Gray ascribed both the cytonet and vesicular coats to a fixation artefact. If we are now to believe that vesicle coats are a genuine feature of the in vivo state, as Pearse's work suggests, then Gray's earlier description of the cytonet (J. Neurocytol., 1, 363; 1972 ) is also unchallenged. Having seen many of Professor Gray's micrographs I have never doubted its existence. However, contrary to the suggestion made by Pearse and Bretscher I have no desire to make anyone believe in the cytonet. I do believe that it is important to point out an alternative to the restricted view afforded by their premature neologism for the coat/cytonet protein. 